\title{
Dampak Begadang Terhadap Kesehatan Mental Remaja Kecamatan Mojosari
}

\author{
Imamul Arifin S,Sy. M.HI. \\ Politeknik Elektronika Negeri \\ Surabaya \\ E-mail: $\underline{\text { mamul@pens.ac.id }}$
}

\author{
Agung Nugraha Nursya'bana \\ Politeknik Elektronika Negeri \\ Surabaya \\ E-mail: nugrahagung09@gmail.com
}

\author{
Faried Dirgantara Putra \\ Politeknik Elektronika Negeri \\ Surabaya \\ E-mail : fariddecker@gmail.com
}

\begin{abstract}
Abstrak
Remaja merupakan proses peralihan dari anak anak menuju dewasa. Pada masa ini seseorang mengalami perubahan emosi yang signifikan dan tidak stabil. Biasanya remaja suka melakukan hal hal seenaknya sendiri tanpa mempertimbangkan dampak panjangnya contohnya seperti sering melakukan begadang. Bila begadang terlalu sering maka seseorang tersebut dapat mengalami berbagai gangguan kesehatan tubuh dan berpengaruh juga ke kesehatan mentalnya. Penelitian ini bertujuan untuk mengetahui dampak-dampak dari Begadang Terhadap kesehatan Mental Remaja serta memberikan jalan keluar dari gangguan untuk remaja yang terjebak dalam siklus begadang dan tidak dapat kembali ke jam normalnya
\end{abstract}

Kata Kunci: Remaja, Begadang, Kesehatan Mental

\begin{abstract}
Adolescence is a process of transition from children to adults. At this time a person experiences significant emotional changes and is unstable. Usually, teenagers like to do things on their own without considering the long-term impact, for example, often staying up late. If you stay up too often, a person can experience various health problems and affect their mental health. This study aims to determine the impacts of staying up late on the mental health of adolescents and to provide a way out of the disorder for adolescents who are trapped in the cycle of staying up late and unable to return to their normal hours.
\end{abstract}


Keywords: Teenagers, Staying Up Late, Mental Health

\section{PENDAHULUAN}

Remaja merupakan proses peralihan dari anak anak menuju ke dewasa (https://kbbi.web.id/, 2021). Pada masa remaja seseorang memiliki tingkat emosi yang tidak stabil, dan biasanya suka melakukan hal hal yang diinginkannya tanpa memikirkan dampak panjang terhadap dirinya dan orang lain.

Karena sifat Remaja yang ingin tahu akan hal baru maka tak menutup kemungkinan para remaja melakukan Begadang, ingin tahu seperti apa bila tidak tidur di malam hari dikarenakan pada saat anak anak dilarang oleh orang tuanya untuk tidak tidur di malam hari atau yang disebut juga begadang

Begadang ini merupakan kegiatan terjaga di malam hari atau tidak tidur di malam hari sembari melakukan kegiatan tertentu seperti membuat laporan, belajar, dan lain lain (https://kbbi.web.id/, 2021).

Hal ini bila dilakukan secara sering dapat menganggu kinerja tubuh seperti jantung, bilamana Kesehatan tubuh terganggu maka akan memberikan dampak buruk juga untuk kesehatan mental

Dengan adanya fenomena tersebut, penulis ingin menganalisis dan mengkaji korelasi antara Begadang terhadap kesehatan mental Remaja

\section{METODE}

Pada penelitian ini partisipan adalah Remaja Kecamatan Mojosari. Partisipan berjumlah 8 Remaja laki laki dan 2 Remaja Perempuan.

Data dalam penelitian ini dikumpulkan dengan menggunakan metode survey. Survey dibuat dengan menggunakan aplikasi Google Form yang disebarkan menggunakan media sosial kedalam grup grup Perkumpulan Remaja Mojosari. Partisipan diminta untuk membaca dan memilih pilihan yang ada.

Data yang didapat diolah dengan menggunakan metode kuantitatif. Data ditampilkan dengan menggunakan diagram diagram untuk memudahkan analisa. Analisa data dilakukan dengan pendekatan deskriptif korelasioanal untuk mengetahui hubungan antar data dan jurnal yang ada. 
Berdasarkan grafik 2. $90 \%$ Remaja Mojosari Sering begadang dan. $10 \%$ Remaja Mojosari jarang begadang. Dari grafik dapat diketahui bahwa hampir semua Remaja Mojosari yang kami servey sering melakukan Begadang.

\section{HASIL DAN PEMBAHASAN}

\section{Hasil}

\section{Jenis kelamin

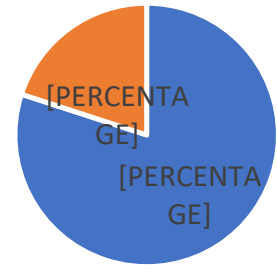 \\ - Laki laki - Perempuan}

Gafik 1. Data Jenis Kelamin Responden

Berd asarkan grafik 1. Jumlah Jumlah partisipan laki-laki adalah sebanyak $80 \%$ dan perempuan sebanyak 20\%. Dari grafik itu juga dapat disimpulkan jumlah Remaja laki laki lebih banyak ketimbang jumlah Remaja Perempuan

Berikut ini adalah grafik dari seberapa sering remaja mojosari melakukan begadang.

\section{Seberapa sering begadang}

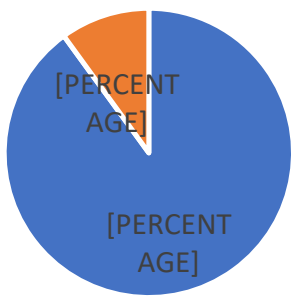

- Sering - Jarang

Grafik 2. Data Seberapa sering begadang

\section{Terjadinya gangguan pada} waktu tidur

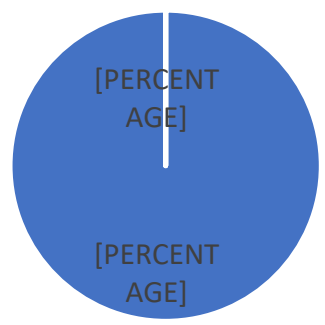

- Waktu tidur berantakan waktu tidur normal

Grafik 3. Terjadinya gangguan pada waktu tidur

Berdasarkan grafik 3. $100 \%$ Remaja Mojosari yang kami survey memiliki waktu tidur yang berantakan.

\section{Faktor penyebab begadang}

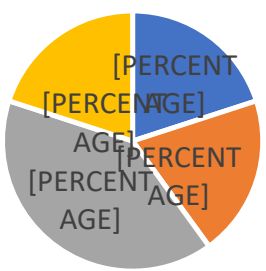

- Bermain game - Menonton film

- Mengerjakan tugas - Bekerja Shift malam

Grafik 4. Faktor Penyebab Begadang

Berdasarkan grafik 4. $20 \%$ Remaja Mojosari Begadang karena bermain game, 20\% Remaja Mojosari Begadang karena 
menonton film, 40\% Remaja Mojosari begadang dikarenakan mengerjakan tugas, dan $20 \%$ sisanya dikarenakan Bekerja pada shift malam.

\section{Harapan waktu tidur kembali normal}

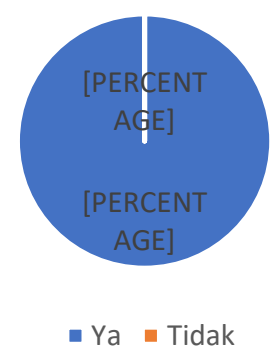

Grafik 5. Harapan waktu tidur kembali normal

Pada grafik 5, 100\% Dari Remaja Mojosari mengharapkan jam tidurnya kembali ke waktu tidur yang normal yakni tidur pukul 21.00 dan bangun pada waktu menjelang subuh

\section{PEMBAHASAN}

Dari survey yang dilakukan dapat dipastikan beberapa dari Remaja Mojosari sering melakukan begadang. Hal ini bila dilakukan secara sering dan berkelanjutan akan memberikan dampak buruk bagi kesehatan, apabila kesehatan dari fisiknya terganggu maka akan berdampak pula pada kondisi mental remaja tersebut.

Berbagai gangguan kesehatan mental yang disebabkan oleh begadang antara lain:

\section{Stress}

Stress merupakan bentuk gangguan mental yang disebabkan oleh berbagai macam faktor seperti tekanan dari keluarga, lingkungan sekitar. Stress disini adalah gangguan suasana hati yang mula mula biasa saja menjadi gelisah (Musradinur, 2016). Biasanya stress dapat menyebabkan seseorang sulit untuk berkonsentrasi, tidak percaya diri, dan menjadi tekanan pikiran pada remaja

Banyaknya pikiran membuat remaja susah untuk tidur, entah itu urusan tugas, sekolah, kuliah, pekerjaan, atau memiliki masalah lain hal ini dapat membuat remaja terganggu tidurnya, seperti tiba-tiba terbangun karena banyak pikiran, sehingga tidurnya tidak maksimal dan remaja terjebak kedalam lingkaran pola tidur yang tidak normal.

\section{Depresi}

Depresi adalah suatu gangguan mental yang ditandai dengan berbagai ciri ciri:

- Selalu merasa bersalah atas semua yang terjadi dalam dirinya ataupun orang lain;

- Merasa rendah diri dan menganggap dirinya sendiri tidak berguna atau tidak berharga;

- Memiliki rasa cemas yang tinggi, rasa cemas ini tidak normal atau bisa disebut cemasnya berlebihan;

- Memiliki suasana hati atau mood yang sangat buruk secara berkelanjutan dalam jangka yang panjang.

(Aries Dirgayunita, 2016).

3. Menimbulkan anxiety

Anxiety atau yang bisa dibilang kekhawatiran dan rasa takut yang berlebihan yang dapat mengganggu kehidupan sehari hari (Stefany Livia Prajogo, dkk 2021). anxiety ini dapat menyebabkan gangguan pada fungsi tubuh seperti halnya orang yang mengalami anxiety biasanya jantungnya berdebar debar tidak normal, nafasnya tersengal sengal. 
Kedua hal ini sangat berbahaya bagi kesehatan tubuh.
Didalam Al-Qur'an sendiri terdapat berbagai tuntunan dari Allah SWT mengenai tentang tidur sesuai dengan QS An Naba' ayat $9-11$

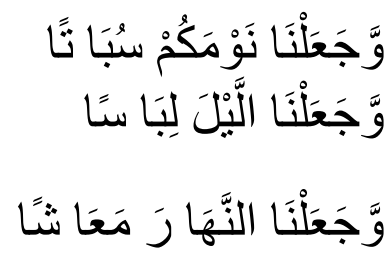

"dan Kami menjadikan tidurmu untuk istirahat,"

(QS. An-Naba' 78: Ayat 9)

"dan Kami menjadikan malam sebagai pakaian,"

(QS. An-Naba' 78: Ayat 10)

"dan Kami menjadikan siang untuk mencari penghidupan,"

(QS. An-Naba' 78: Ayat 11)

Didalam ayat tersebut Allah telah memberi petunjuk kepada hambanya bahwa pada waktu malam sebagai tidur, dan tidur ini merupakan proses istirahat dari segala macam kegiatan duniawi, lalu pada siang hari Allah SWT menuntun hambanya untuk mencari penghidupan seperti bekerja, belajar, dan aktivitas yang lain. Kita sebagai hamba Allah sebaiknya mengikuti anjurannya sebagai tuntunan dalam kehidupan sehari hari.

Allah SWT juga memberi petunjuk kepada hambanya mengenai tidur pada QS Ar-Rum ayat 23

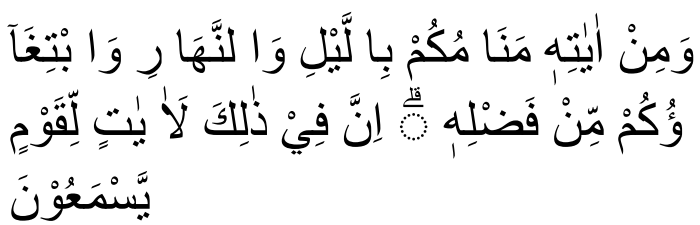

"Dan di antara tanda-tanda (kebesaran)-Nya ialah tidurmu pada waktu malam dan siang hari dan usahamu mencari sebagian dari karunia-Nya. Sungguh, pada yang demikian itu benar-benar terdapat tanda-tanda bagi kaum yang mendengarkan."

(QS. Ar-Rum 30: Ayat 23)

Dari beberapa ayat di atas dapat memperkuat bahwasanya Allah telah memberi petunjuk tentang tidur, dan petunjuknya pun tidak hanya sekali namun berkali kali, kita sebagai hambanya hendaknya mengikuti tuntunan dari Allah dikarenakan segala hal yang berasal dari Allah adalah yang terbaik untuk kita.

Solusi untuk menghindari permasalahan kesehatan mental yang disebabkan karena terlalu sering begadang sesuai dengan tuntunan nabi antara lain:

1. Memadamkan lampu

Memadamkan lampu dapat mempercepat tidur dikarenakan pada saat lampu dimatikan maka hormon melatonin akan diproduksi secara alami selama tidur, Hormon melatonin ini adalah hormon yang mengatur ritme tidur. Dan Rasullah SAW pun pernah bersabda "Padamkanlah lampu-lampu di malam hari pada saat kalian tidur malam, kuncilah pintu dan tutuplah bejana, makanan dan minuman."

2. Posisi Tidur ke arah Kanan Tidur menghadap ke kanan sangat dianjurkan oleh Rasulullah. Hal ini disebabkan karena jantung di sebelah kiri, maka tidur menghadap kanan dapat mencegah jantung tertindih. Dalam HR. Al-Bukhari no. 247 dan Muslim no. 2710, Nabi Muhammad SAW mengatakan agar 
"Berbaringlah di atas rusuk sebelah kananmu"

\section{Tidur Lebih Awal Selepas Sholat}

Isya

Anjuran Rasul untuk tidur lebih awal setelah melakukan sholat isya jika tidak ada kepentingan lain, daripada menghabiskan waktu untuk hal hal yang tidak berguna "Bahwasanya Rasulullah SAW membenci tidur malam sebelum sholat Isya dan berbincang-bincang (yang tidak bermanfaat) setelahnya." (HR. Bukhari No. 568 dan Muslim No. 647).

Solusi dari segi makanan untuk para remaja yang sedang mengalami kecemasan yang berlebihan sehingga dapat mengganggu jam tidurnya sebagai berikut:

1. Mengkonsumsi makanan alamiah yang banyak mengandung sedatif.

Sedatif sendiri adalah senyawa kimia yang terdapat pada tumbuhan obat tradisional yang memiliki fungsi sebagai penenang (Efraim Samson dkk, 2019). jadi mengkonsumsi makanan yang mengandung sedatif dapat menenangkan seseorang yang sedang mengalami kecemasan atau rasa takut yang berlebihan. Makanan yang mengandung sedatif antara lain daun kayu galala, kangkung.

\section{PENUTUP}

\section{Simpulan}

Berdasrkan hasil survey dan analisis yang dilakukan pada Remaja Mojosari dapat disimpulkan bahwa banyak faktor yang dapat membuat remaja melakukan begadang dan jika kegiatan ini berlangsung terlalu lama dapat menyebabkan dampak buruk bagi kesehatan serta mental, maka dari itu penulis memberikan saran untuk mengurangi begadang serta menerapkan pola tidur sesuai tuntunan nabi dan mengatur konsumsi makanan yang bermanfaat agar membantu proses percepatan tidur.

\section{Saran}

Berdasarkan penelitian dari jurnal ,pembahasan, dan kesimpulan penulis akan memberikan beberapa saran yang diharapkan dapat mencegah maupun mengurangi masalah dari begadang terhadap kesehatan mental:

1. Menerapkan pola tidur sesuai dengan tuntunan Nabi Muhammad SAW

Nabi Muhammad adalah seorang utusan Allah kepada umat manusia, beliau sebagai suri tauladan manusia, hendaknya kita sebagai manusia mencontoh segala hal dari beliau hingga hal sekecilpun seperti pola tidur beliau

2. Mengkonsumsi makanan yang mengandung sedatif

3. Memperbanyak dzikir

Dikarenakan dzikir dapat membuat hati menjadi tenang, insyaallah dengan berdzikir mengingat Allah dapat meringankan beban pikiran. Dan akan keluar dari permasalahan tersebut.

\section{Daftar Pustaka}

Badan Pengembangan dan Pembinaan Bahasa, K. P. (2021). Retrieved from https://kbbi.kemdikbud.go.id/

Dirgayunita, A. (2016). Depresi: Ciri, Penyebab dan Penangannya. Journal An-nafs: Kajian dan Penelitian Psikologi.

MUSRADINUR. (2016). STRES DAN

CARA MENGATASINYA DALAM PERSPEKTIF. Jurnal Edukasi.

Stefany Livia Prajogo, A. Y. (2021). Metaanalisis Efektivitas Acceptance 
and Commitment Therapy untuk

Menangani Gangguan Kecemasan

Umum. PSIKOLOGIKA.

QS. An-Naba' 78: Ayat 9-11

QS. Ar-Rum 30: Ayat 23

HR. Al-Bukhari no. 247 dan Muslim no.

2710

HR. Bukhari No. 568 dan Muslim No. 647

Samson , E., Ridwan, W. A. H., \& Baszary

, C. D. U. (2019). POTENSI SEDATIF-

HIPNOTIK DAUN KAYU GALALA

(ERYTHRINA LITHOSPERMA)

SEBAGAI KANDIDAT OBAT

INSOMNIA. Jurnal Matematika Sains Dan

Teknologi, 20(2), 84-94.

https://doi.org/10.33830/jmst.v20i2.166.201

9 